\title{
Analysis of intra-specific variation in the fatty acid profiles of Borrelia burgdorferi
}

\author{
M. Anne Livesley, ${ }^{1}$ Ian P. Thompson, ${ }^{1}$ Lise Gern $^{2}$ and Patricia A. Nuttall ${ }^{1 *}$ \\ 'NERC Institute of Virology and Environmental Microbiology, Mansfield Road, Oxford, OXI $3 S R, U K$ \\ ${ }^{2}$ Université de Neuchâtel, Institut de Zoologie, Chantemerle 22, Case Postale 2, 2007 Neuchâtel, Switzerland
}

(Received 11 March 1993; revised 13 May 1993; accepted 4 June 1993)

\begin{abstract}
Analysis of the fatty acid methyl esters (FAMEs) of bacteria is a commonly used chemotaxonomic technique. Application of this methodology to spirochaetes associated with Lyme borreliosis revealed distinct clusters corresponding to three genetically distinguished groups: Borrelia burgdorferi sensu stricto, B. garinii, and the VS461 group. However, $B$. garinii formed a common group with $B$. hermsii, a relapsing fever spirochaete, and VS461 grouped with $B$. turicatae and $B$. parkeri, two other relapsing fever spirochaetes. The diversity in fatty acid profiles of Lyme disease spirochaetes has implications for the protean clinical manifestations of the disease.
\end{abstract}

\section{Introduction}

Many methods have been used to compare different isolates of Borrelia burgdorferi, the aetiological agent of Lyme borreliosis. Apparently unique isolate-specific cleavage patterns of restriction-enzyme-digested whole $B$. burgdorferi DNA have been obtained (Le Febvre et al., 1989). Plasmid profiles have been found to differ between isolates but also to change upon prolonged cultivation (Schwan et al., 1988). The use of the polymerase chain reaction (PCR) has shown differences in the reactivity of different isolates of $B$. burgdorferi with chromosomally derived primers. Southern blot analysis of restriction patterns of the genes coding for rRNA have also revealed differences between isolates (Postic et al., 1990). Differences in the levels of reactivity of $B$. burgdorferi isolates with monoclonal antibodies have also been shown (Wilske et al., 1988).

More recently phylogenetic analysis based on 16S rRNA sequences of $B$. anserina, $B$. coriaceae, $B$. hermsii and B. burgdorferi (North American and European isolates) has been performed (Marconi \& Garon, $1992 a, b$ ). Further attempts to classify $B$. burgdorferi isolates have involved the use of multilocus enzyme electrophoresis (Boerlin et al., 1992), polymorphism of outer surface membranes (Peter \& Bretz, 1992) and PCR

*Author for correspondence. Tel. (0865) 512361; fax (0865) 59962.

Abbreviations: ACA, acrodermatitis chronica atrotrophicans; MIS, microbial identification system; FAME, fatty acid methyl ester.
(Rosa et al., 1991; Welsh et al., 1992). Three DNA groups (genospecies) have been delineated based on rRNA gene restriction patterns, protein electrophoresis patterns and patterns of reactivity with murine monoclonal antibodies - B. burgdorferi sensu stricto, B. garinii sp. nov. and Group VS461 (Baranton et al., 1992).

The classification of B. burgdorferi has been extensively investigated in view of the clinical manifestation of $B$. burgdorferi infection in humans. The symptoms of Lyme borreliosis differ in Europe when compared to North America (Steere, 1989). In Europe, acrodermatitis chronica atrophicans (ACA; a chronic skin disorder) and neuroborreliosis are common (Ackermann et al., 1988; Asbrink \& Hovmark, 1988). By contrast, in North America Lyme arthritis is common whereas this is comparatively rare in Europe (Steere, 1989). The classification of Borrelia species associated with relapsing fevers has not been properly investigated and it has been suggested by some workers that $B$. hermsii, $B$. turicatae and $B$. parkeri are not valid species on the basis of DNA-DNA hybridization studies (Hyde \& Johnson, 1984).

Most of the methods which have been used to classify B. burgdorferi have relied upon the product of a single chromosomal locus, or a specific gene sequence, although multilocus enzyme electrophoresis has been utilized (Boerlin et al., 1992). One phenotypic method of classification which has recently been applied to Borrelia species is based on the analysis of fatty acid profiles (Livesley et al., 1993). The advantage of this method is that the fatty acid profile of bacteria is a stable indication 
Table 1. Sources and suppliers of the Borrelia isolates used in this study

\begin{tabular}{|c|c|c|c|c|}
\hline Borrelia isolate & Source & Country & Supplier* & Group $\dagger$ \\
\hline B. burgdorferi ACA-1 & $\mathrm{ACA}$ & Sweden & S. Cutler ${ }^{1}$ & 1 \\
\hline B. burgdorferi 328 & $\begin{array}{l}\text { Ixodes } \\
\text { dammini }\end{array}$ & USA & S. Cutler & 1 \\
\hline B. burgdorferi $\mathrm{HB} 19$ & Human blood & USA & S. Cutler & 1 \\
\hline B. burgdorferi $\mathrm{HB} 4$ & Human blood & USA & S. Cutler & 1 \\
\hline $\begin{array}{l}B . \text { burgdorferi B31 } \\
\text { type strain }\end{array}$ & I. dammini & USA & ATCC 35210 & 1 \\
\hline B. burgdorferi JD1 & I. dammini & USA & B. Johnson ${ }^{2}$ & 1 \\
\hline B. turicatae & $\begin{array}{l}\text { Ornithodoros } \\
\text { turicata }\end{array}$ & USA & T. Schwan ${ }^{3}$ & 2 \\
\hline B. parkeri & $O$. parkeri & USA & T. Schwan & 2 \\
\hline B. burgdorferi $\operatorname{Ir} 210$ & I. ricinus & CIS & E. I. Korenberg ${ }^{4}$ & 3 \\
\hline B. burgdorferi 21305 & I. dammini & USA & S. Cutler & 3 \\
\hline B. burgdorferi M32 & I. ricinus & Netherlands & S. Carter ${ }^{5}$ & 3 \\
\hline VS461 & I, ricinus & Switzerland & D. Postic ${ }^{6}$ & 3 \\
\hline B. burgdorferi $\mathrm{M} 27$ & I. ricinus & Netherlands & S. Carter & 3 \\
\hline B. hermsii CON-1 & Human & USA & T. Schwan & 4 \\
\hline B. hermsii HS1 & o. hermsii & USA & T. Schwan & 4 \\
\hline B. burgdorferi NE550 & I. ricinus & Switzerland & L. Gern ${ }^{7}$ & 5 \\
\hline B. burgdorferi NE2 & I. ricinus & Switzerland & L. Gern & 5 \\
\hline B. burgdorferi NE4R4 & I. ricinus & Switzerland & L. Gern & 5 \\
\hline B. burgdorferi NE58P8 & I. ricinus & Switzerland & L. Gern & 5 \\
\hline B. burgdorferi NE58 & I, ricinus & Switzerland & L. Gern & 5 \\
\hline B. garinii 20047 & I. ricinus & France & D. Postic & 5 \\
\hline
\end{tabular}

* 1, Charing Cross Hospital, London, UK; 2, Centers for Disease Control, Fort Collins, USA, 3, Rocky Mountain Laboratories, Hamilton, Montana, USA; 4, Gamaleya Institute for Epidemiology \& Microbiology, Moscow, CIS; 5, University of Liverpool, UK; 6, Institut Pasteur, Paris, France; Université de Neuchâtel, Switzerland.

$\dagger$ The group number corresponds with that shown in Fig. 1 .

of the phenotype when the bacteria under study are grown in controlled culture conditions (Welch, 1991). Fatty acid metabolism is not under plasmid control and the presence of certain fatty acids has been shown to correlate with taxonomic conventions (Drucker, 1976; Lechevalier, 1977). The analysis of fatty acid profiles is one of the techniques of chemotaxonomy (Cacciopuoti et al., 1991) and has been used successfully with Xanthomonas maltophilia, Klebsiella terrigena, Erwinia herbicola and Microbacterium lacticum (Thompson et al., 1993), numerous Gram-negative bacteria (Stoakes et al., 1991), Leptospira spp. (Cacciopuoti et al., 1991) and as a means of distinguishing members of the spirochaete family (Livesley $e t$ al., 1993). In this paper we use fatty acid profiles to demonstrate inter- and intra-species variation within the genus Borrelia.

\section{Methods}

Culture of bacterial strains. Leptospira interrogans (serogroup icterohaemorrhagiae) and Serpulina hyodysenteriae (S75/I and B78 isolates) were cultured as previously described (Livesley et al., 1993).

Borrelia species (Table 1) including the $B$. burgdorferi reference strain B3! (ATCC 35210) were grown in a modified Barbour-Stoenner-Kelly medium as described previously (Livesley et al., 1993). Microaerophilic conditions were established by dispensing the media into $10 \times 100 \mathrm{~mm}$ tubes, where $6 \mathrm{ml}$ occupied approximately $75 \%$ of the volume available. The Borrelia were incubated at $34{ }^{\circ} \mathrm{C}$ for the period needed to generate a cell density of $10^{8}$ organisms $\mathrm{ml}^{-1}$. The same batches of medium enrichment (CMRL 1066) were used in all experiments. Spirochaetes were harvested by centrifugation $(1000 \mathrm{~g}, 15 \mathrm{~min})$ when grown to a highly motile condition as determined by dark-field microscopy. Fifty milligrams (wet wt) of spirochaetes were required for each fatty acid profile (Livesley et al., 1993).

Fatty acid methyl ester (FAME) extraction. Long-chain fatty acids extracted from bacteria require derivatization before gas-liquid chromatography. FAME derivatives were prepared using the procedure described by Kloepper et al. (1992).

Gas-liquid chromatography. FAMEs were analysed with a Hewlett Packard series II gas chromatograph model 5890A equipped with a $25 \mathrm{~m} \times 0.22 \mathrm{~mm} \times 0.33 \mu \mathrm{m}$ phenyl methyl silicone capillary column and integrator 3392A as described by Livesley et al. (1993).

Reproducibility of FAME analysis. For the reference isolates the reproducibility of the FAME profiles was analysed by using repeated injections from extracts derived from three separate cultures. All remaining isolates were analysed by repeat injections of three separatc extracts derived from one culture of the isolate, under standard conditions. For each peak in the chromatogram the coefficient of variation (standard deviation/mean) $\times 100$ was calculated (Mukwaya $\&$ Welch, 1989). Clustering was accomplished by the unweighted pair group for arithmetic averages (Sneath \& Sokal, 1973). Similarity and relatedness were expressed as Euclidian distance values, as defined by Austin \& Priest (1986). The fatty acid profile for Pseudomonas aureofaciens was obtained from the MIDI library as described by Thompson et al. (1992). 


\section{Results and Discussion}

Previous work has demonstrated that FAME analysis can be used to distinguish spirochaetes at the sub-generic level (Livesley et al., 1993). The use of this technique to demonstrate intra-species variation amongst Borrelia is shown in Fig. 1.

Analyses of the profiles of 17 isolates together with borreliae associated with tick-borne relapsing fevers $(B$. hermsii, B. parkeri and B. turicatae) revealed a number of groups (Fig. 1, Table 1). The FAME compositions of representatives of each group are summarized in Table 2. Borrelia parkeri and $B$. turicatae grouped together (group 2), but the two B. hermsii isolates (group 4) did not form an obvious cluster. Further analyses need to be undertaken with isolates of $B$. hermsii and with $B$. turicatae and $B$. parkeri when more isolates of these latter two species become avalable. For the Lyme disease spirochaetes, clusters shown in the dendrogram (Fig. 1) support the delineation of $B$. burgdorferi sensu stricto (group 1), B. garinii (group 5), and Group VS461

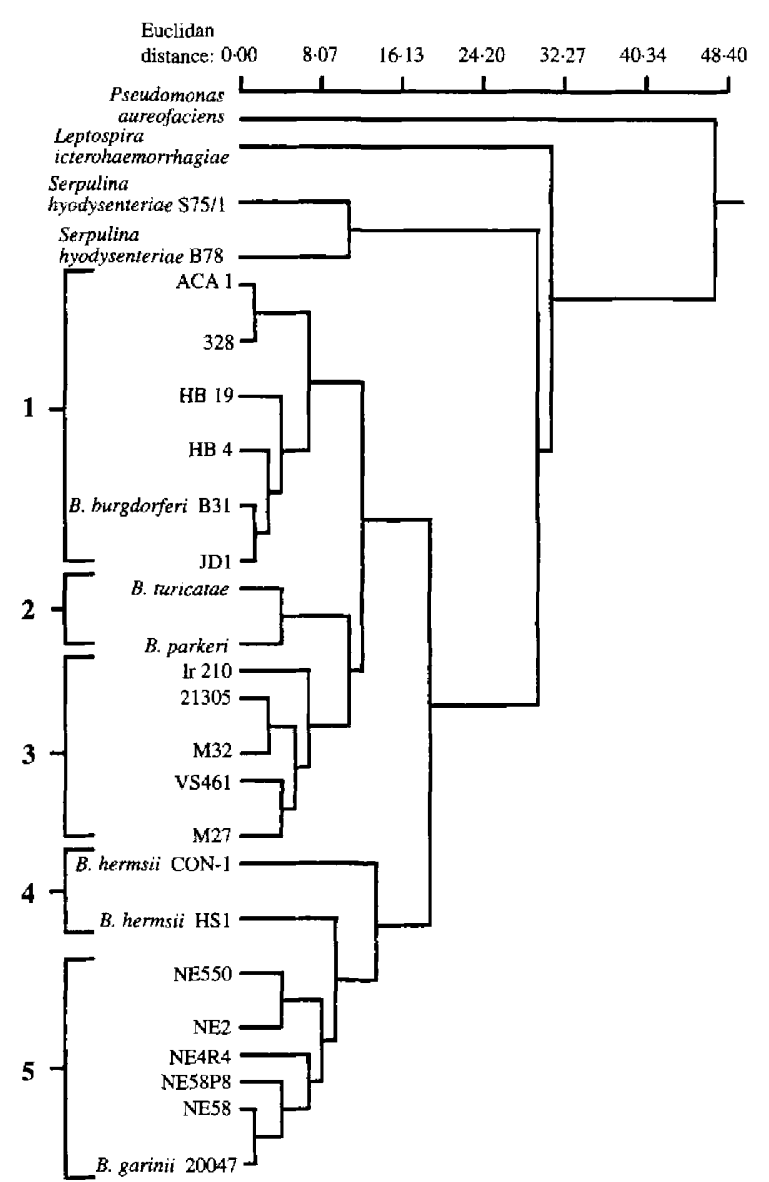

Fig. 1. Dendrogram of the FAME profile relatedness of reference isolates of Borrelia used in this study. Isolates of Leptospira interrogans (serogroup icterohaemorrhagiae) and Serpulina hyodysenteriae were included as representative examples of other spirochaetes. Pseudomonas aureofaciens was included in the dendrogram as an outgroup. (group 3), proposed by Baranton et al. (1992). The FAME profiles of reference members of these groups $(B$. burgdorferi sensu stricto B31, B. garinii 20047 and VS461) are shown in Fig. 2. FAME profiles of $B$. hermsii, $B$. parkeri and $B$. turicatae are shown in Livesley et al. (1993).

Geographical clustering of Lyme disease spirochaetes was observed. All the isolates from the Neuchâtel and Staatswald areas of Switzerland clustered together with B. garinii 20047, an isolate from France (group 5). North American isolates clustered together (group 1), as did another group of European isolates: M32, M27, VS461 and Ir210 (group 3). The exceptions were the American isolate 21305 in group 3, and the Swedish isolate ACA-1 in group 1. Few of the isolates used in the FAME analysis have been examined by other techniques. The grouping of the Swiss isolate NE2 with B. garinii 20047 was also observed by multilocus enzyme electrophoresis (Boerlin et al., 1992) but, in the same study, the Swedish isolate ACA-1 clustered with VS461 rather than with $B$. burgdorferi sensu stricto (group 1; Fig. 1).

The clustering of American and European isolates of B. burgdorferi has been demonstrated by other methods such as 16S rRNA sequencing (Marconi \& Garon, $1992 a, b)$. These workers distinguished between $B$. burgdorferi on one branch of a phylogenetic tree and $B$. hermsii, $B$. coriaceae and $B$. anserina on a separate branch. The results of the cluster analysis shown in Fig. 1 represent the first reported attempt to group Lyme disease spirochaetes on the basis of their fatty acid content. Clustering of isolates based on other phenotypic characteristics, such as multilocus enzyme electrophoresis (Boerlin et al., 1992) and antigenic variability (Wilske et al., 1988), has been demonstrated. However, the former study (Boerlin et al., 1992) did not include $B$. hermsii, B. parkeri and B. turicatae, and the latter study (Wilske et al., 1988) included these species but utilized monoclonal antibodies which react with a single epitope, hence the results are not directly comparable with those shown in Fig. 1. None of the methods used to date have demonstrated a complete correlation between clustering pattern and either the source (e.g. species of tick, clinical sample) or the geographical location of the isolate.

Surprisingly, borreliae associated with Lyme disease were not distinguished as a group from the relapsing fever spirochaetes examined. Group 5 (containing $B$. garinii) showed a closer relationship with $B$. hermsii than with the other two groups of Lyme disease spirochaetes, and group 3 (containing VS461) was closest to $B$. turicatae and B. parkeri. Apart from their differences in disease associations, Lyme disease spirochaetes are transmitted by ixodid ticks (Ixodes spp.) and relapsing fever spirochaetes are transmitted by argasid ticks (Ornithodoros spp.) (Kelly, 1984). Considerable varia- 
Table 2. Fatty acids (as percentage of the total FAME area $\pm S D$ ) present in representative isolates of each of the groups delineated in Fig. 1

A summed feature refers to a group of fatty acids not resolved by the extraction procedure used in this study. Coefficients of variation were $\leqslant 8.01$ for peaks which occupied $\geqslant 3.00 \%$ of the total FAME percentage area.

\begin{tabular}{|c|c|c|c|c|c|c|}
\hline Fatty acid & $\begin{array}{l}\text { Shorthand } \\
\text { designation }\end{array}$ & $\begin{array}{l}\text { B. burgdorferi } \\
\text { sensu stricto } \\
\text { (1) }\end{array}$ & $\begin{array}{l}\text { B. turicatae } \\
\text { B. parkeri } \\
\text { (2) }\end{array}$ & $\begin{array}{c}\text { VS461 } \\
\text { (3) }\end{array}$ & $\begin{array}{l}\text { B. hermsii } \\
\text { (4) }\end{array}$ & $\begin{array}{l}\text { B. garinii } \\
\text { (5) }\end{array}$ \\
\hline Dodecanoate & $12: 0$ & & & $0.30 \pm 0.06$ & & $0.39 \pm 0.06$ \\
\hline Tetradecanoate & $14: 0$ & $1 \cdot 34 \pm 0.22$ & $1 \cdot 10 \pm 0 \cdot 07$ & $2 \cdot 34 \pm 0.22$ & $1.20 \pm 0.08$ & $1.78 \pm 0.03$ \\
\hline 12-Methyltetradecanoate & $15: 0$ anteiso & & & & & $0 \cdot 12 \pm 0-02$ \\
\hline Pentadecanoate & $15: 0$ & $1.09 \pm 0.07$ & $0.75 \pm 0.03$ & $1 \cdot 16 \pm 0 \cdot 15$ & $0.74 \pm 0.06$ & $0.80 \pm 0.02$ \\
\hline Hexadecenoate & $16: 1$ & $0.23 \pm 0.01$ & & $0.38 \pm 0.06$ & $0.22 \pm 0.12$ & $0 \cdot 35 \pm 0.03$ \\
\hline 14-Methylpentadecanoate & $16: 0$ iso & & & & $0.13+0.02$ & $0.16 \pm 0.07$ \\
\hline cis-Hexadec-9-enoate & $16: 1(9 \mathrm{c})$ & $1.39 \pm 0.23$ & $0-61 \pm 0.03$ & $2 \cdot 23 \pm 0 \cdot 15$ & $1 \cdot 14 \pm 0.09$ & $1.93 \pm 0.09$ \\
\hline Hexadecanoate & $16: 0$ & $57.62 \pm 2.18$ & $48.93 \pm 1.29$ & $50.88 \pm 2.09$ & $43.29 \pm 1.63$ & $39 \cdot 83 \pm 0 \cdot 12$ \\
\hline 14-Methylhexadecanoate & $17: 0$ anteiso & $0 \cdot 37 \pm 0 \cdot 12$ & $0.21 \pm 0.02$ & $0.45 \pm 0.14$ & $0.17+0.02$ & \\
\hline Heptadecenoate & $17: 1$ & & $0.22 \pm 0.03$ & & $0.34 \pm 0.04$ & $0-36 \pm 0.02$ \\
\hline Heptadecanoate & $17: 0$ & $1.08 \pm 0.08$ & $1.25 \pm 0.05$ & $1 \cdot 33 \pm 0.12$ & $1 \cdot 18 \pm 0.07$ & $1.14 \pm 0.03$ \\
\hline cis-Octadec-9-enoate & $18: 1(9 \mathrm{c})$ & $23 \cdot 28 \pm 0.62$ & $31 \cdot 11 \pm 1 \cdot 27$ & $22.56 \pm 1.08$ & $26 \cdot 48 \pm 1.03$ & $23.02 \pm 0.08$ \\
\hline Octadecanoate & $18: 0$ & $2.79 \pm 0.68$ & $6 \cdot 39 \pm 0.32$ & $6 \cdot 24 \pm 0.50$ & $0.02 \pm 0.01$ & $9 \cdot 70 \pm 0.68$ \\
\hline Arachidonate & $20: 45,8,11,14 \mathrm{c}$ & & $0.41 \pm 0.02$ & $0.18 \pm 0.06$ & $0.59 \pm 0.03$ & $0.28 \pm 0.03$ \\
\hline Summed feature 6 & & $5 \cdot 30 \pm 0 \cdot 32$ & $9.25 \pm 0.63$ & $11.67 \pm 0.35$ & $15 \cdot 31 \pm 0.75$ & $19 \cdot 52 \pm 0.5$ \\
\hline
\end{tabular}
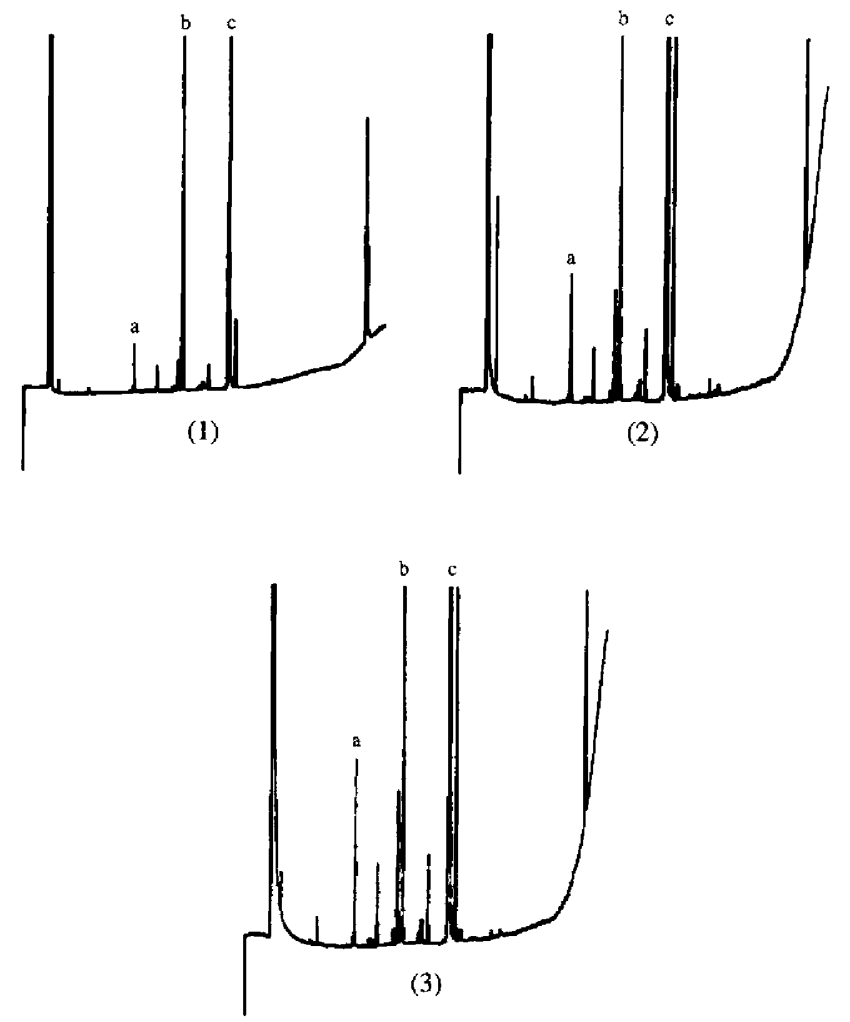

Fig. 2. Representative FAME profiles of reference isolates of: (1) $B$. burgdorferi sensu stricto B31, (2) B. garinii 20047, (3) VS461. Three fatty acid peaks are labelled for purposes of comparison: (a) tetradecanoate, (b) hexadecanoate, (c) cis-octadec-9-enoate.

bility in the peptidase, glycosidase and esterase activities of nine Lyme disease spirochaetes, and similarities with B. hermsii, have been reported (Stanek et al., 1992).
Some metabolic enzymes are likely to be involved in fatty acid synthesis and metabolism and the diversity in specific enzyme activities may help explain the clusters derived from analyses of fatty acid profiles. Currently, there are insufficient published data to determine whether the FAME clusters result from a convergence in phenotype of the different borrelial types, or if they reflect genetic relationships.

Besides their application in chemotaxonomy, fatty acids are of interest because of their role in the pathogenesis of several bacterial diseases (Lechevalier, 1977). The differentiation of Borrelia using fatty acids, given their involvement in membrane structure, may possibly aid an explanation of the differing manifestations of Lyme borreliosis, for example arthritis being a more common symptom in the United States (Steere, 1989) and ACA and neuroborreliosis being more common in Europe (Ackermann et al., 1988; Asbrink \& Hovmark, 1988). In Leptospira the presence of serovarspecific glycolipids has been demonstrated (Ono et al., 1987) whilst in B. burgdorferi Wheeler et al. (1993) showed antibody reactivity to fractions of chloroform/ methanol extracts, using sera from Lyme disease patients, and speculated on the possible role of this lipidcontaining antigen in autoreactive-mediated pathogenesis. Obviously, fatty acids provide a source of diversity among Lyme disease spirochaetes that needs to be explored further in relation to the protean clinical manifestations of the disease.

We are grateful to the Health and Safety Executive (HSE) for funding M.A.L., the Department of the Environment for funding I.P.T. and the Swiss National Science Foundation (SNSF) for funding 
L. G. The collaboration was supported by the SNSF/British Council Joint Research Programme. We also thank all the suppliers of the Borrelia isolates as shown in Table 1.

\section{References}

AckermanN, R., Rehse-Kupper, B., Gollmer, E. \& SChmidt, R. (1988). Chronic neurologic manifestations of Erythema Migrans borreliosis. Annals of the New York Academy of Sciences 539, 16-23.

Asbrink, E. \& HovmarK, A. (1988). Early and late cutaneous manifestations in Ixodes borne borreliosis (Erythema migrans borreliosis, Lyme borreliosis). Annals of the New York Academy of Sciences 539, 4-15.

Austin, B. \& Priest, F. (1986). Modern Bacterial Taxonomy. Wokinghtam, UK: Van Nostrand Reinhold.

Baranton, G., Postic, D., Saint Girons, I., Boerlin, P., Piffaretti, J. C., Assous, M. \& Grimont, P. A. D. (1992). Delineation of Borrelia burgdorferi sensu stricto, Borrelia garinii sp. nov. and group VS461 associated with Lyme Borreliosis. International Journal of Systematic Bacteriology 42, 378-383.

Boerlin, P., Peter, O., Bretz, A. G., Postic, D., Baranton, G. \& PiffaretTI, J. C. (1992). Population genetic analysis of Borrelia burgdorferi by multilocus enzyme electrophoresis. Infection and Immunity 60, 1677-1683.

Cacciopuoti, B., Ciceroni, L. \& Attard Barbini, D. (1991). Fatty acid profiles - a chemotaxonomic key for classification of strains of the Leptospiraceae. International Journal of Systematic Bacteriology 41, 295-300.

DRUCKER, D. B. (1976). Gas liquid chromatographic chemotaxonomy. Methods in Microbiology 9, 51-125.

HYDE, F. W. \& JoHnson, R. C. (1984). Genetic relationship of Lyme disease spirochaetes to Borrelia, Treponema and Leptospira spp. Journal of Clinical Microbiology 20, 151-154.

KelLy, R. T. (1984). Spirochetales. In Bergey's Manual of Systematic Bacteriology, vol. 1, pp. 57-61. Edited by N. R. Krieg \& J. G. Holt. Baltimore: Williams \& Wilkins

Kloepper, J. W., RodriGo, R., McInroy, J. A. \& YOUng, R. W. (1992). Rhizosphere bacteria antagonistic to soybean cyst (Heterodera glycines) and root knot (Meloidogyne incognita) nematodes: identification by fatty acid analysis and frequency of biological control activity. Plant and Soil 139, 75-84.

LeCheValier, M. P. (1977). Lipids in bacterial taxonomy. A taxonomist's view. Critical Reviews in Microbiology 5, 109-210.

Le Febvre, R. B., Perno, G. C. \& Johnson, R. C. (1989). Characterization of Borrelia burgdorferi isolates by restriction endonuclease analysis and DNA hybridization. Journal of Clinical Microbiology 27, 636-639.

Ljvesley, M. A., Thompson, I. P., Bailey, M. J. \& Nuttall, P. A. (1993). Comparison of the fatty acid profiles of Borrelia, Serpulina and Leptospira species. Journal of General Microbiology 139, 889-895.

MarCoN, R. T. \& GARON, C. F. (1992a). Identification of a third genomic group of Borrelia burgdorferi through signature nucleotide analysis and $16 \mathrm{~S}$ rRNA sequence determination. Journal of General Microbiology 138, 533-536.
MarCon, R. T. \& Garon, C. F. (1992b). Phylogenetic analysis of the genus Borrelia: a comparison of North American and European isolates of Borrelia burgdorferi. Journal of Bacteriology 174, 241-244.

Mukwaya, G. M. \& Welch, D. F. (1989). Subgrouping of Pseudomonas cepacia by cellular fatty acid composition. Journal of Clinical Microbiology 27, 2646-2649.

Ono, E., Takase, H., Naiki, M. \& Yanagawa, R. (1987). Purification, characterization and serological properties of a glycolipid antigen reactive with a serovar specific monoclonal antibody against Leptospira interrogans serovar canicola. Journal of General Microbiology 133, 1329-1336.

Peter, O. \& Bretz, A. G. (1992). Polymorphism of outer surface proteins of Borrelia burgdorferi as a tool for classification. Zentralblatt für Bakteriologie 277, 28-33.

Postic, D., Edlinger, C., Richaud, C., Grimont, F., Dufresne, Y., Perolate, P., Baranton, G. \& Grimont, P. A. D. (1990). Two genomic species in Borrelia burgdorferi. Research in Microbiology 141, 465-475.

Rosa, P. A., Hogan, D. \& Schwan, T. G. (1991). Polymerase chain reaction analyses identify two distinct classes of Borrelia burgdorferi. Journal of Clinical Microbiology 29, 524-532.

Schwan, T. G., Burgdorfer, W. \& Garon, C. F. (1988). Changes in infectivity and plasmid profile of the Lyme spirochaete Borrelia burgdorferi as a result of in vitro cultivation. Infection and Immunity 56, 1831-1836.

SNEATH, P. H. A. \& SoKal, R. R. (1973). Numerical Taxonomy: the Principles and Practice of Numerical Classification, pp. 230-234. San Francisco: W. H. Freeman.

Stanek, G., Manafi, M. \& Koch, C. (1992) cited by Penn, C. W., Bassford, P. J., Yelton, D. B., DunN, J., Nelson, D. R., FukunaGa, M. \& StaneK, G. Genetic approaches to cell biology and metabolism of spirochetes. Research in Microbiology 143, 605-613.

Steere, A. C. (1989). Lyme disease. New England Journal of Medicine $321,586-596$.

Stonkes, L., Kelly, T., Schieven, B., Harley, D., Ramos, M., Lannigan, R., Groves, D. \& Hussain, Z. (1991). Gas liquid chromatographic analysis of cellular fatty acids for identification of Gram-negative anaerobic bacilli. Journal of Clinical Microbiology 29, 2636-2638

Thompson, I. P., Batley, M. J., Ellis, R. J. \& Purdy, K. J. (1993). Subgrouping of bacterial populations by cellular fatty acid composition. FEMS Microbiology Ecology 102, 75-84.

WELCH, D. (1991). Applications of cellular fatty acid analysis. Clinical Microbiological Reviews 4, 422-438.

Welsh, J., Pretzman, C., Postic, D., Saint Grrons, I., Baranton, G. \& MCLellaND, M. (1992). Genetic fingerprinting by arbitrarily primed polymerase chain reaction resolves Borrelia burgdorferi into three distinct phyletic groups. International Journal of Systematic Bacteriology 42, 370-377.

Wheeler, C. M., Monco, J. C. G., Benach, J. L., Golightly, M. G., Habicht, G. S. \& STEERE, A. C. (1993). Non-protein antigens of Borrelia burgdorferi. Journal of Infectious Diseases 167, 665-674.

Wilske, B., Preac-Mursic, V., Schierz, G., Kuhbeck, R., Barbour, A. G. \& Kramer, M. (1988). Antigenic variability of Borrelia burgdorferi. Annals of the New York Academy of Sciences 539, 126-143. 